\title{
Explaining differential effects of tiotropium on mortality in COPD
}

The editorial by Jenkins and Beasley ${ }^{1}$ makes a speculative recommendation that tiotropium Respimat should not be prescribed in the treatment of chronic obstructive pulmonary disease (COPD), being primarily based on meta-analysis where mortality was not the primary end point. The meta-analysis by Singh $e t a l^{2}$ 
reported that treating 124 patients per annum with tiotropium Respimat $5 \mathrm{ug}$ resulted in one additional death, although the associated $95 \%$ CI of 52 to 5682 clearly indicates that the data are not particularly robust. In considering the risk-benefit ratio of tiotropium one has to consider the seed and the soil, in terms of the degree of systemic exposure and the predisposing cardiovascular status. There is a lack of biological plausibility for the apparent disconnect between the apparent increased mortality with tiotropium Respimat on the one hand, but reduced mortality with the Handihaler on the other. Such an opposite effect on putative cardiotoxicity seems hard to justify on the basis of a $22 \%$ difference in systemic exposure (as area under curve (AUC)) between the devices.

If tiotropium was inherently cardiotoxic at current therapeutic doses, then one would presumably see some sort of increased mortality signal in real life even with the Handihaler device due to systemic exposure, for example in susceptible hypoxic patients with concomitant cardiovascular disease. This hypothesis is however not consistent with a real life retrospective cohort study using an National Health Service (NHS) database of patients with COPD in Tayside, Scotland, where 1857 patients with COPD received tiotropium $(90 \%$ via dry powder inhaler) together with inhaled corticosteroid plus long acting $\beta$-agonist and 996 who received inhaled corticosteroid plus long acting $\beta$-agonist alone, with a mean follow-up of 4.65 years. ${ }^{3}$ There were 949 (33\%) patients who died during the study period. The adjusted hazard ratio (HR) for all-cause mortality was 0.74 (95\% 0.63 to 88 ) with tiotropium as a timedependent covariate. Matched propensity scoring analysis showed a HR of 0.64 (95\% CI 0.53 to 0.77 ), thus confirming the benefit of tiotropium in reducing mortality. Moreover, the adjusted HR for death due to cardiovascular disease was 0.49 (95\% CI 0.33 to 73 ) and for death due to respiratory disease was 0.70 (95\% CI 0.57 to 0.84 ). Pointedly in the double and triple therapy groups, there were respectively $43.1 \%$ and $47.1 \%$ of COPD patients who had a history of concomitant cardiovascular disease, with respective mean oxygen saturations of $92.5 \%$ and $91.3 \%$ - that is, these were clearly patients who would be at risk from potential cardiotoxicity with tiotropium.

Thus rather than extolling the merits of data torture to substantiate premature recommendations about the use of withdrawal of tiotropium Respimat, we would advocate waiting for more definitive data from the ongoing TIOSPIR study. ${ }^{4}$ In the meantime, on a more pragmatic basis, for those patients who prefer to use the Respimat device, physicians could perhaps use a $2.5 \mathrm{ug}$ dose of tiotropium instead, which would exhibit lower systemic bioavailability than the Handihaler device, which has been shown to reduce mortality on COPD in a real life setting.

\section{Brian J Lipworth, Philip M Short}

Asthma and Allergy Research Group, Medical Research Institute, University of Dundee, Ninewells Hospital, Dundee, Scotland

Correspondence to Dr Brian Lipworth, Asthma and Allergy Research Group, Medical Research Institute, University of Dundee, Ninewells Hospital, Dundee DD1 9SY, Scotland; brianlipworth@gmail.com

Competing interests BJL has received placebo inhalers as an unrestricted educational gift from Boehringer Ingelheim, payment from Boehringer to attend an Advisory Board and financial support from Boehringer to attend the Winter British Thoracic Society meeting 2012. PMS received financial support from Boehringer Ingelheim to attend the European Respiratory Society meeting in 2009.

Provenance and peer review Not commissioned; internally peer reviewed.

To cite Lipworth BJ, Short PM. Thorax 2013;68:589-590.

Received 21 December 2013

Accepted 10 January 2013

Published Online First 31 January 2013

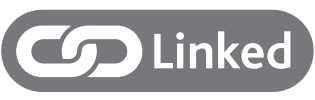

http://dx.doi.org/10.1136/thoraxjnl-2013-203238

Thorax 2013;68:589-590.

doi:10.1136/thoraxjn-2012-203176

\section{REFERENCES}

1 Jenkins CR, Beasley R. Tiotropium Respimat increases the risk of mortality. Thorax 2013;68:5-7.

2 Singh S, Loke YK, Enright PL, et al. Mortality associated with tiotropium mist inhaler in patients with chronic obstructive pulmonary disease: systematic review and meta-analysis of randomised controlled trials. BMJ 2011;342:d3215.

3 Short PM, Williamson PA, Elder DH, et al. The impact of tiotropium on mortality and exacerbations when added to inhaled corticosteroids and long-acting beta-agonist therapy in COPD. Chest 2012;141:81-6.

4 Comparison of Tiotropium in the HandhiHaler versus the Respimat in chronic obstructive pulmonary disease. http://clinicaltrials.gov/show/NCT01126437 (accessed 24 January 2013). 